\title{
COMPOSTOS FENÓLICOS EM DIFERENTES MARCAS DE CERVEJA: COMPARAÇÃO QUALITATIVA DE DIFERENTES MARCAS E SUA RELAÇÃO COM A SAÚDE HUMANA
}

MACIEL, Denis Cardoso; ELÓI, Ligia Mara Henrique. Discentes do Curso de Farmácia do Centro Universitário de Votuporanga/Campus Centro.

E-mail: dc_maciel@hotmail.com; ligia-he@hotmail.com.

JORDÃO, Christiane de Oliveira. Docente do Curso de Farmácia do Centro Universitário de Votuporanga/ Campus Centro, Rua Pernambuco, 1594 - Centro, CEP 15500-006.

E-mail: cojord@ hotmail.com

\begin{abstract}
RESUMO
Atualmente vem se observando o intenso interesse em alimentos que, além da nutrição, ofereçam atividades funcionais em relação à prevenção de alguns distúrbios fisiológicos. A presença dos compostos fenólicos em alguns alimentos faz com que os mesmos sejam capazes de prevenir doenças como câncer, arteriosclerose, doenças cardíacas, inflamações, entre outros benefícios, pelo fato de os mesmos agirem como agentes antioxidantes no organismo. Sendo a cerveja umas das bebidas mais consumidas pelos brasileiros, e por apresentar em sua composição compostos do tipo fenólicos, este estudo objetivou realizar uma análise qualitativa e comparativa da composição destes em cinco diferentes marcas de cervejas do tipo Pilsen mais consumidas pela população brasileira, relacionando-os com seus efeitos à saúde humana. Foram utilizados os métodos de Reações Cromogênicas - RCR e Cromatografia em Camada Delgada - CCDA para identificação dos compostos, métodos que se mostraram eficientes perante a proposta do trabalho. Encontraram-se nas cervejas a presença de compostos do grupo dos flavonóides, catequinas e taninos, além da presença de ácidos fenólicos, como o cafeico, vanílico e ferúlico. Tais substâncias fazem com que a cerveja adquira um potencial antioxidante que apresenta benefícios à saúde de quem a consome, indiferentemente da marca, já que todas apresentaram semelhante padrão de compostos do tipo fenólicos, podendo assim desprover principalmente de ação antiarterioscleróticas, anti-inflamatórias, anticarcinogênicas, antitrombóticas, entre outras.
\end{abstract}

Palavras-chave: Cerveja; Compostos fenólicos; Saúde humana.

PHENOLIC COMPOUNDS IN DIFFERENT BEER BRANDS: A QUALITATIVE COMPARISON OF DIFFERENTE BRANDS AND THEIR RELATIONSHIP WITH HUMAN HEALTH

\section{Abstract}

Nowadays, we have observed a great interest in food that, besides nutrition, provides functional activities in relation to the prevention of some physiological disorders. The presence of phenolic compounds in some kinds of food makes them able to prevent some diseases, such as cancer, arteriosclerosis, heart diseases, inflammations, as well as other benefits, because they behave like antioxidant agents in the organism. Considering that beer is one of the most consumed drinks by Brazilian people and it also has as part of its composition some compounds like the phenolic ones, our research aimed at performing a qualitative and comparative analysis using the phenolic compounds in five different brands of "Pilsen" beer that are more consumed by the population, in relation to their effects to health. To identify the compounds, two methods were used, chromogenic reactions and thin layer chromatography, methods that were efficient for this research. Compounds from the group of flavonoids, flavanones, catechins and tannins, beside some phenolic acids, such as the caffeic, the para-coumarica and 
ferulic ones were found in beer. Such substances provide beer with an antioxidant power that presents benefits for the health of those who drink it, no matter the brand, because they showed the same pattern of phenolic compounds, having, this way, mainly an antiatherosclerotic, anti-inflammatory, anticarcinogenic, antithrombotic action, among others.

Keywords: Beer; Phenolic Compounds; Human health.

\section{INTRODUÇÃo}

Apreciada por muitos na atualidade e indispensável para os momentos de lazer de grande parte dos brasileiros, a cerveja, que movimenta bilhões no mercado mundial, é uma bebida que se originou da cultura mediterrânea há milhares de anos. Evidências históricas apontam que seu uso na Antiguidade não era exclusivo somente como uma bebida, mas que a mesma também apresentava propriedades e fins medicinais (FREITAS et al., 2006).

A cerveja é um produto obtido através do processo de fermentação alcoólica do mosto de cereal maltado, na grande maioria o da cevada, podendo ser adicionados outros cereais e substâncias adjuvantes para condicionar as características desejadas ao produto. Um dos principais componentes da cerveja é também a água, pois a sua boa qualidade está diretamente relacionada com a qualidade final do produto (FREITAS et al., 2006).

As cervejas mais consumidas e que predominam no mercado brasileiro são as do tipo Pilsen, as popularmente conhecidas como "cervejas claras", sendo produzidas em larga escala pela indústria cervejeira no país (KUCK, 2008). O Brasilé um dos maiores produtores de cerveja, ficando atrás somente de países desenvolvidos como China (a campeã em produção), Estados Unidos, Alemanha e Rússia. Já em relação ao consumo, ocupa posição entre os primeiros no ranking e, assim sendo, devido ao seu grande consumo, apresenta imenso interesse de pesquisa, tanto em caráter para melhora de sua produção, quanto em relação aos seus efeitos a saúde humana (SIQUEIRA; BOLINI; MACEDO, 2008).

O equilíbrio entre os compostos da cerveja é essencial para sua qualidade e condiz com seus aspectos sensoriais, assim, podendo ou não ser aceita pelo consumidor quanto as suas características lábeis. Possui um complexo de compostos que lhes proporciona moderado sabor e aroma e sua composição está diretamente relacionada à qualidade, sendo um sério problema para indústria brasileira a perda por sabores indesejáveis (ARAÚJO; SILVA; MINIM, 2003).

Os processos de oxidação que ocorrem nos alimentos é fator influenciável na vida de prateleira de muitos produtos da indústria alimentícia. Diante desse aspecto, os compostos fenólicos presentes na cerveja apresentam grande influência no seu processo de conservação, sendo de suma importância econômica para as indústrias, já que a oxidação desses podem alterar as características sensoriais da mesma, como o sabor, cor e o aroma. Um exemplo é a oxidação dos taninos que pode levar ao escurecimento da bebida (DEGÁSPARI, 2004; KUCK, 2008).

Uma pesquisa realizada na Universidade Estadual de Campinas - Unicamp analisou as características bioquímicas e sensoriais de três marcas de cerveja durante o processo de envelhecimento, no qual se conclui que a cerveja pode perder cerca de $50 \%$ de sua capacidade antioxidante até o fim de sua vida de prateleira, que dura cerca de seis meses. Adiminuição da concentração de compostos fenólicos na cerveja está diretamente ligada as suas características organolépticas, em especiais os flavonoides (SANTOS; 2007).

Em relação aos benefícios à saúde pelo consumo da cerveja, estes se relacionam com a presença de agentes antioxidantes que reagem com os radicais livres no organismo. Os radicais livres soltos no plasma podem reagir com o DNA, RNA, proteínas ou quaisquer outras substâncias oxidáveis, podendo contribuir para o aparecimento de doenças degenerativas ou até mesmo o envelhecimento. Os antioxidantes são obtidos pelo organismo através da dieta de alimentos que os contenham em sua 
composição, sendo a principal forma de obtê-los, e necessário, pois o sistema antioxidante não supre sozinho essa necessidade do organismo. As vitaminas, compostos fenólicos e os carotenoides são os principais antioxidantes obtidos na dieta (PEREIRA; VIDAL; CONSTANT, 2009).

De acordo com o publicado no jornal da Unicamp, a cerveja ainda pode ser também fonte de vitamina $\mathrm{B} 9$, devido à presença de folatos, compostos equivalentes ao ácido fólico, que são muito importantes no combate à anemia e doenças cardiovasculares (GARDENAL, 2010). Já o etanol, considerado o grande vilão da cerveja, também pode apresentar benefícios à saúde, pois pode interferir no metabolismo de HDL - bom colesterol - e na fibrinoloses, podendo apresentar papel importante na absorção de compostos fenólicos (FREITAS et al., 2006).

Tem-se observado atualmente grande interesse na pesquisa e estudo de compostos fenólicos e alimentos que os contenham em sua composição, devido ao fato de esses alimentos apresentarem muito mais que sua função nutritiva, também auxiliando e prevenindo em distúrbios fisiológicos, apresentando atividades funcionais como ação antiarterioscleróticas, antiinflamatórias, anticarcinogênicas, antitrombóticas e antiosteoporóticas (FURLONG et al., 2003).

Consumidores e produtores têm apresentado atualmente um grande interesse nos compostos fenólicos. Os polifenóis são os antioxidantes encontrados em maior quantidade na dieta, sendo as principais fontes produtos como os sucos, vinhos, chocolates, chás e a então discutida cerveja. Ultimamente, vem se associando uma relação entre alimentos ricos em compostos fenólicos na prevenção de doenças, como inflamações, doenças cardiovasculares, etc. (SIQUEIRA; BOLINI; MACEDO, 2008).

Os polifenóis presentes na cerveja são adquiridos principalmente da casca da cevada e do lúpulo. Dentre eles podemos destacar os ácidos fenólicos e os flavonoides, as antocianinas e seus derivados produtos de oxidação e os flavonóis. Além de contribuírem para a saúde dos consumidores, também têm influência sobre a conservação da cerveja, podendo retardar o seu processo de envelhecimento. Aparecem também outros compostos, como os taninos, por exemplo (FREITAS et al., 2006).

A importância desses compostos para a saúde e de seu desempenho na produção de cerveja justifica uma maior atenção na sua caracterização analítica e bioquímica, o que objetivou este trabalho a realizar uma análise qualitativa de identificação de compostos fenólicos presentes nas diferentes marcas de cerveja do tipo Pilsen mais consumidas pela população brasileira e relacioná-los com efeitos na saúde humana.

\section{Materiais e mÉTOdos}

Foram analisadas neste trabalho 5 diferentes marcas de cervejas do tipo Pilsen, dentre as mais consumidas no mercado brasileiro, provenientes de embalagem de alumínio de $350 \mathrm{ml}$ que apresentassem tempo de prateleira não muito equidistantes, variando-se no máximo em até dez dias a data de fabricação entre as mesmas, e o tempo de prateleira não podia passar de 30 dias da fabricação.

Os métodos analíticos utilizados para a identificação qualitativa dos compostos foram os descritos abaixo e realizados em triplicatas. O método de RCR foram baseados nos métodos descritos por MATOS (1997) e os de CCDA realizados pela otimização de metodologias descritas por PEREIRA (2010).

\section{Determinação dos compostos fenólicos por RCR - Reações Cromogênicas \\ Operações Preliminares}

Concentraram-se amostras de cerveja em béqueres de $10 \mathrm{ml}$ cada em chapa de aquecimento até se obter a metade do volume. Pipetaram-se sete porções de 3-4 $\mathrm{ml} \mathrm{em} \mathrm{tubos} \mathrm{de} \mathrm{ensaio} \mathrm{numerados.} \mathrm{Foram}$ submetidos o conteúdo dos tubos de ensaio aos seguintes testes:

\section{Testes para fenóis e taninos (Teste 1)}

Tomou-se o tubo número 1 e juntaram três gotas de solução alcoólica de $\mathrm{FeCl}_{3}$ a 0,1 mol. Agitou-se bem e observou-se qualquer variação de sua cor ou formação de precipitado abundante, escuro. Foi 
comparado com um teste em branco, isto é, usando apenas água e cloreto férrico.

- Coloração variável entre o azul e o vermelho é indicativo da presença de fenóis, quando o teste "branco" for negativo.

- Precipitado escuro de tonalidade azul indica a presença de taninos pirogálicos (taninos hidrolizáveis) e verde, a presença de taninos flobabênicos (taninos condensados ou catequéticos).
Testes para antocianinas, antocianididinas e flavonoides (Teste 2)

Tomaram-se os tubos de números 2,3 e 4 , e foi acidulado um deles a pH 3 com solução de $\mathrm{HCl}$ a 0,1 mol, alcalinizado outro a pH 8,5 e o terceiro a pH 11 com solução de $\mathrm{NaCla} 0,1$ mol. Observou-se qualquer mudança da coloração do material.

- Aparecimento de cores diversas indica a presença de vários constituintes, de acordo com a Tabela 1.

Tabela 1 - Teste para determinação de antocianinas, antocianididinas e flavonoides.

\begin{tabular}{|c|c|c|c|}
\hline \multirow[b]{2}{*}{ Constituintes } & \multicolumn{3}{|c|}{ Cor em meio } \\
\hline & ácido (3) & alcalino $(8,5)$ & alcalino (11) \\
\hline $\begin{array}{l}\text { Antocianinas e } \\
\text { Antocianidinas }\end{array}$ & Vermelha & Lilás & Azul Púrpura \\
\hline $\begin{array}{l}\text { Flavonas, Flavonoides e } \\
\text { Xantonas }\end{array}$ & & & Amarela \\
\hline Chalconas e Auronas & Vermelha & & Verm elho Púrpura \\
\hline Flavonóis & & & Vermelho laranja \\
\hline
\end{tabular}

Fonte: Dados de pesquisa.

Testes para leucoantocianidinas, catequinas e flavanonas (Teste 3)

Tomaram-se os tubos numerados 5 e 6 , e foi acidulado o primeiro por adição de $\mathrm{HCl}$ (concentração) até pH 1-3 e alcalinizado o outro com $\mathrm{NaOH}$ (concentração) até pH 11. Foram aquecidos com auxílio de uma lâmpada de álcool durante 2-3 minutos, cuidadosamente. Observou-se qualquer modificação na cor, por comparação com os tubos correspondentes usados no teste anterior.

- Aparecimento ou intensificação de cor indica a presença de constituintes especificados na Tabela 2. 
Compostos fenólicos em diferentes marcas de cerveja...

Tabela 2 - Teste para determinação de leucoantocianidinas, catequinas e flavanonas.

\begin{tabular}{|l|c|c|}
\hline \multirow{2}{*}{ Constituintes } & \multicolumn{2}{c|}{ Cor em meio } \\
\cline { 2 - 3 } & ácido (1-3) & alcalino (11) \\
\hline Leucoantocianidinas & Vermelha & \\
\hline Catequinas (Taninos catequéticos) & Pardo-amarelo & Vermelho laranja \\
\hline Flavononas & & . \\
\hline \multicolumn{2}{|l|}{ Obs.: No caso da presença de ambos, um constituinte pode mascarar a cor indicativa de outro. } \\
\hline
\end{tabular}

Fonte: Dados de pesquisa.

Testes para flavonóis, flavanonas, flavanonóis e xantonas (Teste 4)

Adicionaram-se ao tubo de número7 alguns centigramas de magnésio granulado ou em fita e 0,5 $\mathrm{ml} \mathrm{de} \mathrm{HCl}$ concentrado. Aguardou-se o término da reação indicada pelo fim da efervescência e foi observado por comparação mudança na cor da mistura da reação nos tubos 5 e 7 (acidificados).

- Aparecimento ou intensificação de cor vermelha é indicativo da presença de flavonóis, flavanonas, flavanonóis elou xantonas, livres de seus heterosídios.

Análises cromatográficas das substâncias fenólicas nos extratos hidroalcoólicos

$\mathrm{Na}$ análise por Cromatografia em camada delgada analítica - CCDA, realizada pela otimização de metodologias descritas por Stahl (1969), foram utilizadas em cromato placas com sílica gel 60 F254
(Merck). Como fase móvel, utilizou-se o sistema de solvente: tolueno : metanol (7:3). O ensaio foi realizado em triplicata para permitir a revelação das placas por nebulização com os reativos de vanilina sulfúrica (vanilina a $2 \%$ em etanol e adicionada de $10 \%$ de ácido sulfúrico) e a mistura (1:1) de $\mathrm{FeCl}_{3}$ (cloreto férrico $)+\mathrm{K}_{3} \mathrm{Fe}(\mathrm{CN})_{6}$ (ferricianeto de potássio). Após nebulização dos reativos, revelou-se a presença de diferentes substâncias fenólicas nos extratos analisados. Utilizou-se, como parâmetro de avaliação, a cor desenvolvida na sequência de reveladores empregados para a detecção do perfil cromatográfico dos extratos hidroalcoólicos (PEREIRA, 2010, p.22-23.)

Na Tabela 3 estão apresentados os testes com reveladores químicos para a determinação de alguns dos ácidos fenólicos por cromatografia em camada delgada analítica (TUZEN; OZDEMIR, 2003 apud PEREIRA, 2010). 
Tabela 3 - Testes para determinação de ácidos fenólicos por Cromatografia em Camada Delgada.

\begin{tabular}{|c|c|c|}
\hline Ácidos & $\begin{array}{c}\mathrm{FeCl}_{3}+ \\
\mathrm{K}_{3} \mathrm{Fe}(\mathrm{CN})_{6}\end{array}$ & Vanilina $+\mathrm{H}_{2} \mathrm{SO}_{4}$ \\
\hline Cinâmico & Amarelo & - \\
\hline Ferúlico & Azul escuro & Lilás claro \\
\hline Vanílico & Azul & Rosa \\
\hline para-cumárico & Azul & Lilás claro \\
\hline para-hidroxi benzoico & Azul claro & - \\
\hline Cafeico & Azul escuro & Lilás \\
\hline
\end{tabular}

Fonte: Dados de pesquisa.

\section{Resultados E Discussão}

Nas diferentes amostras de cervejas analisadas por este trabalho, os compostos fenólicos encontrados por RC estão dispostos na Tabela 4, enquanto os identificados por CCDA estão presentes na Tabela 5.

As diferentes marcas de cervejas analisadas apresentaram padrão de substâncias fenólicas basicamente semelhante, quando realizados todos os testes propostos. As técnicas realizadas demonstraram ser abrangentes, reprodutíveis e de fácil execução, sendo adequadas para o procedimento de identificação do perfil de substâncias presentes nas diferentes amostras analisadas. Mas vale ressaltar que, em alguns casos, a presença de um dos compostos pode mascarar a detecção de outro nos testes. Sendo assim, para casos que necessitem da identificação de determinado composto em si, é necessário que se valha de outra metodologia de identificação mais específica. A baixa concentração dos compostos nas amostras também podem se tornar empecilho na sua identificação.

Dentre os compostos fenólicos que podem estar presentes na cerveja, foi possível identificar pelas análises a presença de compostos pertencentes ao grupo dos flavonoides, flavonas, flavononas, além das catequinas e taninos flobabênicos. Registrou-se também a presença de ácidos fenólicos como cafeico, ferúlico e para-cumárico, assim demonstrados nas Tabelas 4 e 5. 
Tabela 4 - Compostos fenólicos identificados por RCR.

\begin{tabular}{|c|c|c|cc|c|}
\hline \multicolumn{2}{|c|}{ Compostos fenólicos identificados nas amostras de cerveja do tipo Pilsen } \\
\hline & $\begin{array}{c}\text { Amostra } \\
\text { A }\end{array}$ & $\begin{array}{c}\text { Amostra } \\
\text { B }\end{array}$ & $\begin{array}{c}\text { Amostra } \\
\text { C }\end{array}$ & $\begin{array}{c}\text { A mostra } \\
\text { D }\end{array}$ & $\begin{array}{c}\text { Amostra } \\
\text { E }\end{array}$ \\
\hline Fenóis & - & - & - & - & - \\
\hline Taninos flobabênicos & + & + & + & + & + \\
\hline Taninos Pirogálicos & - & - & - & - & - \\
\hline Anto cianinas e Antocianidinas & - & - & - & + & + \\
\hline Flavonas, Flavonoides & + & + & + & - & - \\
\hline e Xantonas & - & - & - & - & - \\
\hline Chalconas e Auronas & - & - & - & - & - \\
\hline Flavonóis & - & - & - & + & + \\
\hline Leucoantocianidinas & + & + & + & + & + \\
\hline Catequinas & + & + & + & + \\
\hline
\end{tabular}

Fonte: Dados de pesquisa.

Tabela 5 - Ácidos fenólicos identificados por CCDA.

\begin{tabular}{|c|c|c|c|c|c|c|}
\hline \multicolumn{7}{|c|}{ Ácidos presentes na amost ras de cerveja do tipo Pilsen } \\
\hline & Cafeico & Ferúlico & Vanílico & Cinâmico & $\begin{array}{c}\text { para- } \\
\text { cumárico }\end{array}$ & $\begin{array}{c}\text { para-hidroxi } \\
\text { benzoico }\end{array}$ \\
\hline Amost ra A & + & + & - & - & + & - \\
\hline Amostra B & + & + & - & - & + & - \\
\hline Amost ra C & + & + & - & - & + & - \\
\hline Amost ra D & + & + & - & - & + & - \\
\hline Amostra E & + & + & - & - & + & - \\
\hline
\end{tabular}

Fonte: Dados de pesquisa.

Os compostos fenólicos presentes na cerveja provêm do lúpulo e, na sua grande maioria, do malte da cevada, fazendo com que a bebida se torne uma boa fonte de polifenóis. Porém, os compostos derivados lúpulo são mais fáceis de serem caracterizados que os da cevada, pois durante o processamento da bebida eles podem sofrer mudanças, tornando-os de difícil caracterização (SIQUEIRA; BOLINI; MACEDO, 2008).
Geralmente os compostos fenólicos são encontrados na cerveja ligados a outros compostos, como ésteres e glicosídeos, mas também é possível encontrá-los em sua forma livre, e algumas substâncias apresentarão maior possibilidade de serem encontradas ou no malte ou no lúpulo. Os derivados de ácidos hidrobenzoicos e ácidos hidroxinâmicos, como, por exemplo, os ácidos ferúlico, para-cumárico e cafeico (identificados pelos testes), são extraídos mais comumente do malte, 
enquanto do lúpulo provêm os flavonóis, chalconas e flavanonas. Igualmente encontráveis, tanto no lúpulo quanto no malte, são os taninos derivados de flavonóis, as catequinas e procianidinas (SIQUEIRA; BOLINI; MACEDO, 2008).

A matéria-prima utilizadaé fundamental na qualidade da composição final dos compostos fenólicos, que também pode ser influenciada pelo processo de fermentação. $\mathrm{O}$ enriquecimento ou empobrecimento na composição desses nos alimentos e bebidas está diretamente relacionado ao processamento no qual foram submetidos para sua produção (SIQUEIRA; BOLINI; MACEDO, 2008).

Os compostos fenólicos atuam como neutralizadores ou sequestradores de radicais livres no organismo ou como queladores de metais de transição. Devido à ressonância do anel aromático presente em suas estruturas, os intermediários formados pela ação de antioxidantes fenólicos adquirem característica estável. O fato de reduzirem radicais livres reativos está relacionado ao poder redutor do grupamento hidroxila, o que lhes confere sua capacidade antioxidante (PEREIRA; VIDAL; CONSTANT, 2009).

As substâncias reativas oxigenadas, assim denominadas as diferentes formas de oxigênio extremamente reativas, estão relacionadas ao aparecimento de doenças como câncer, diabetes, doenças cardíacas, aterosclerose, artrite, entre outras, além de estar ligadas também aos processos de envelhecimento do corpo. Assim sendo, diversos estudos mostraram que, por meio da dieta diária, é possível proteger o organismo dos processos oxidativos que ocorrem naturalmente, através da ingestão de alimentos ricos em antioxidantes, como, por exemplo, os presentes na cerveja (DEGÁSPARI, 2004).

Dentre os compostos fenólicos presentes na bebida, os flavonoides estão entre os mais efetivos no auxílio à saúde humana. Os efeitos farmacológicos e bioquímicos que se destacam são as ações antioxidantes, antiplaquetária e antiinflamatória e seus efeitos antialérgicos. Além disso, os mesmos podem auxiliar beneficamente nos processos de carcinogênese, por meio da inibição de enzimas ligadas a este processo, como a prostaglandina sintetase, a ciclooxigenase e lipoxigenase. Podem atuar também como indutores enzimáticos para algumas enzimas do sitema desentoxicante, como a glutationa Stranferase. Nos alimentos, os mesmos podem atuar sobre a preservação da vitamina $\mathrm{C}$ e impedindo a formação de radicais livres (PEREIRA; VIDAL; CONSTANT, 2009).

Quando falamos de saúde, o flavonoide presente na cerveja que se destaca é a rutina. Esta acaba por produzir efeitos benéficos associados à elevação na atividade da enzima antioxidante superóxido dismutase, assim, diminuindo os fatores de risco para aterosclerose e doenças cardiovasculares, além da elevação do colesterol-HDL (PEREIRA; VIDAL; CONSTANT, 2009).

Compostos monoméricos como a catequina e a quercetina, por serem capazes de quelar radicais livres e inibir a enzima lipoxigenase, que promovem o início da ruptura dos ácidos graxos insaturados, quando liberadas através da polimerização, podem formar novos compostos fenólicos, apresentando de maneira efetiva ação como antioxidantes no organismo (SIQUEIRA; BOLINI; MACEDO, 2008).

Destacam-se, também, os ácidos fenólicos, por possuir atividade antioxidante que auxilia tanto nos alimentos quanto para o organismo. Seus efeitos benéficos estão relacionados à prevenção e tratamento de doenças como o câncer e doenças cardiovasculares (PEREIRA; VIDAL; CONSTANT, 2009). Por serem capazes de sequestrar os radicais livres do organismo, evitando que os mesmos interajam, oxidando o DNA das células, acabam por atuar como anticarcinogênicos (SIQUEIRA; BOLINI; MACEDO, 2008).

Os efeitos anticarcinogênicos dos compostos fenólicos estão diretamente relacionados à prevenção do câncer de pulmão, fígado, esôfago, cólon, mama e pele. Dentre eles se destacam o resveratrol, ácido cafeico, flavonóis e a quercetina, todos compostos presentes na cerveja (ANGELO; JORGE, 2007).

Dos ácidos fenólicos, o ferúlico é o composto mais simples e encontrado em maior abundância na cerveja, totalizando cerca de $50 \%$ ou mais da quantidade total 
de ácidos fenólicos na bebida. Pode ser encontrado em sua forma livre ou na grande maioria ligado a outras substâncias presentes na cerveja, como os açúcares, ácidos orgânicos, substâncias nitrogenadas e íons metálicos, o que dificulta sua quantificação. Devido a sua poderosa ação antioxidante, o acido ferúlico no organismo é considerado um potente fotoprotetor, podendo atuar efetivamente no auxílio à prevenção de cânceres de pele (SIQUEIRA BOLINI; MACEDO, 2008).

Devido à presença de compostos fenólicos, ao consumir a cerveja, mesmo que inconscientemente, uma pessoa está absorvendo para sua dieta substâncias que auxiliamna prevenção de algumas doenças que possam acometer a sua saúde, mostrando assim que a cerveja é uma boa fonte desses compostos, devido à alta concentração deles na mesma. Mas, para se obter uma maior concentração na absorção dos compostos fenólicos através do consumo de cerveja, aconselhase que seja consumida logo após a sua fabricação, pois uma pesquisa realizada confirmou que, após 15 dias de prateleira, perde até $35 \%$ de seus compostos fenólicos, e até o final de seu prazo de validade pode aumentar para 50\% a perda destes (SANTOS, 2007).

O consumo de antioxidantes dietéticos, além de inúmeros benefícios à saúde, torna-se importante devido ao fato de não haver estudos ou evidências de que o consumo de alimentos ricos em antioxidantes acarretem efeitos prejudiciais no decorrer da vida (PEREIRA; VIDAL; CONSTANT, 2009). Mas, em relação à cerveja, é necessário que esse consumo seja moderado, pois a presença do álcool, ao mesmo tempo em que traz benefícios, pode trazer prejuízos à saúde, tanto em curto prazo, como afetar a concentração, diminuir reflexos, provocar alterações fisiológicas, interferir na coordenação motora, quanto a efeitos de longo prazo, como a perda de capacidade neurológica, dependência, alguns tipos de câncer na garganta, esôfago, fígado e degeneração do mesmo, problemas cardiovasculares, entre outros (CARLINI et al., 2001; BALAN; CAMPOS, 2006; GALILEU, 2008).

De acordo com reportagem publicada na "Beer Life", uma revista conceituada sobre o ramo cervejeiro, e outros estudos realizados, tendo como foco o consumo da cerveja e sua relação com saúde, aconselha-se que uma pessoa tome até três doses diárias da bebida, cada dose equivalendo a uma unidade alcoólica (cerca de 12 a 14 g de álcool), assim definido pela Organização Mundial de Saúde-OMS, o que representa a quantidade encontrada em uma latinha de cerveja de $350 \mathrm{~mL}$ (BEER LIFE, 2009; ANDRADE et al., 2009; CUNHA, 2011).

Existe também uma proporção em relação ao sexo, sendo aconselhado que as mulheres consumam duas doses e o homem até três por dia, pois o organismo feminino apresenta menor resistência aos efeitos alcoólicos. Mas vale ressaltar que essa regra possui exceção, já que cada organismo tem um tipo de resposta aos efeitos e à metabolização do álcool (ANDRADE et al., 2009; CUNHA, 2011).

Um estudo realizado aponta que a frequência com a qual é consumida a cerveja também apresenta influência sobre os seus benefícios, afirmando que o ideal seria o consumo da bebida entre três a no máximo cinco dias por semana, e que não há necessidade do aumento da dose para que se consiga absorver mais seus benefícios. Esse intervalo também é necessário, pois o organismo precisa de um tempo de descanso do consumo de álcool, para que possa eliminá-lo do organismo, um processo que pode levar cerca de até 48 horas para ser concluído totalmente (PENNA \& HECKTHEUER, 2004; ANDRADE \& OLIVEIRA, 2009; CUNHA, 2011).

Cabe ressaltar que o consumo de bebida alcoólica não é recomendado a menores de idade, gestantes, idosos, pessoas que apresentem problemas cardíacos ou estejam fazendo uso de qualquer tipo de medicação. Além do que, cerveja não é remédio, por isso, jamais será receitada por um profissional como meio de cura ou prevenção de alguma patogenia. Não se podem confundir os fatos, pois a cerveja não pode se tornar substituto de nenhum tipo de terapia medicamentosa, mas complementar hábitos saudáveis quando feito o consumo de forma regular (ANDRADE; OLIVEIRA, 2009).

Diversos estudos epidemiológicos vêm indicando 
que o consumo de bebidas alcoólicas, como o vinho e a cerveja, ambas ricas em compostos fenólicos, estão diretamente relacionadas à prevenção de algumas doenças, dentre elas as cardiovasculares, bem como a diminuição da taxa de mortalidade, quando comparados os que consomem a bebida com moderação e os que não a consomem ou o fazem em demasia. A prevenção de algumas doenças está cada vez mais relacionada ao consumo de alimentos ricos em polifenóis, o que vem sendo diariamente confirmado por diversos estudos realizados em todo o mundo (SIQUEIRA; BOLINI; MACEDO, 2008).

\section{Conclusões}

A presença de compostos fenólicos na cerveja lhe proporciona uma ação antioxidante, tornando-a capaz de auxiliar em alguns distúrbios fisiológicos do organismo, sem a preocupação dos efeitos do álcool devido a seu baixo teor na bebida. As cinco marcas analisadas apresentaram em sua composição a presença de compostos que são essenciais na dieta humana, não se diferenciando em relação ao perfil de composição. Sendo assim, ao consumi-las, indiferentemente da marca, estarão absorvendo e aproveitando os benefícios oferecidos por esses compostos, desde que o consumo da bebida seja de forma moderada e consciente.

$\mathrm{O}$ intuito do trabalho não é incentivar o uso da bebida alcoólica, no caso a cerveja. A intenção deste foi disponibilizar aos que a consomem informações sobre seus efeitos à saúde e como aproveitá-los de forma eficiente, sem que o consumo da mesma, ao invés de proporcionar benefícios, acabem por provocar ou agravar distúrbios fisiológicos no organismo, afirmando-se que os que não o fazem devem assim continuar.

\section{REFERÊNCIAS}

ANDRADE, L. H. S. G.; SILVEIRA, C. M.; MARTINS, S. S.; STORR C.L.; WANG, Y. P.; VIANA, M. C. Padrões de consumo do álcool e problemas decorrentes do beber pesado episódico no Brasil. Álcool e suas consequências: uma abordagem multiconceitual, 1. ed., Barueri - SP, Minha Editora, 2009, cap. 5, p.103-122.

\section{ANDRADE, A. G.; OLIVEIRAL.G. Principais consequências em longo prazo relacionadas ao cosumo moderado de álcool. Álcool e suas consequências: uma abordagem multiconceitual, 1. ed., Barueri - SP, Minha Editora, 2009, cap. 2, p.37-66}

ANGELO, P. M.; JORGE N. Compostos fenólicos em alimentos - uma breve revisão. Revista Instituto Adolfo Lutz, São Paulo, vol. 66, nº 1, p. 1-9, 2007.

ARAÚJO F.B.P.; SILVAP.H.A. MINIM V.P.R. Perfil sensorial e composição físico-química de cervejas provenientes de dois segmentos do mercado brasileiro. Ciência e Tecnologia de Alimentos, Campinas, 23(2): 121-128, mai-ago. 2003.

BALAN, T. G.; CAMPOS, C. J. G. Padrão de consumo de bebidas alcoólicas entre graduandas de Enfermagem de uma universidade estadual paulista. SMAD - Revista Eletrônica de Saúde Mental, vol. 2, $\mathrm{n}^{\mathrm{o}}$ 2, Artigo 2, 2006. Disponível em: http:// www.revistasusp.sibi.usp.br/pdf/smad/v2n2/ v2n2a03.pdf. Acesso em: 12 out. 2012.

BASTOS, D. H. M.; OLIVEIRA, D. M. Biodisponibilidade de ácidos fenólicos. Química Nova, vol. 34, nº 6, p. 1051-1056, 2011.

CARLINI, E. A.; NAPPO, S. A.; GALDURÓZ, J. C. F.; NOTO, A. R. Drogas psicotrópicas: o que são e como agem?. Revista IMESC, nº 3 , p. 9-35, 2001.

CUNHA, A. J. C. V. O Médico de Família e o Álcool. Universidade do porto, Artigo de Revisão, 
2011, p. 01-22 Disponível em: http://repositorioaberto.up.pt/bitstream/10216/63625/3/ O\%20MDICO\%20DE\%20FAMLIA $\% 20$ E $200 \%$ 20LCOOL \% 20\%20TEMA.pdf Acesso em: 10 out. 2012.

DEGÁSPARI, C.H.; WASCZYNSKYJ, N. Propriedades antioxidantes de compostos fenólicos. Visão Acadêmica, Curitiba, v.5, n.1, p.33-40, jan/ jun. 2004.

FREITAS G.L.; KUSKOSKI, E. M.; GONZAGA, L.; FETT, R. Avaliação da atividade antioxidante de diferentes cervejas aplicando os métodos ABTS e DPPH. Alimento e Nutrição, Araraquara, v.17, n.3, p.303-307, jul./set.2006.

FURLONG, E. B.; COLLA, E.; BORTOLATO, D. S.; BAISCH, A. L. M.; SOARES, L. A. S.; Avaliação do potencial de compostos fenólicos em tecidos vegetais. Vetor, Rio Grande, v. 13, p.105114, 2003.

GARDENAL I. Ingestão de cervejas pode suprir carência de folatos, aponta estudo. Jornal da Unicamp, Campinas, 15/21 mar. 2010, ANO XXIV - No 454, p.9. Disponível em: http:// www.unicamp.br/unicamp/unicamp_hoje/ju/ marco2010/ ju454_pag09.php\# Acesso em: 10 mar. 2012.

KUCK, L. S. Cerveja: sabor e aroma. 2008. 46 páginas. Universidade Federal de Pelotas Departamento de Ciências dos Alimentos Bacharelado em Química de Alimentos, Pelotas, 2008

MATOS, F. J. A. Introdução à Fitoquímica Experimental. Fortaleza, Edições UFC, 2. ed., 1997. 134p.

NEVES, L. C.; ALENCAR, S. M.; CARPES, S. T. Determinação da atividade antioxidante e do teor de compostos fenólicos a flavonóides em amostra de pólen apícola de Apis Mellifera. Brazilian Journal of food technology, VII BMCFB, p. 107-110, 2009. Disponível em: http://bjtt.ital.sp.gov.br/ artigos/ especiais/especia 1_2009_2/ v12ne_t0231.pdf Acesso em: 12 set. 2012.

PENNA, N. G.; HECKTHEUER, L. H. R. Vinho e saúde: uma revisão. Revista Infarma, vol. 16, n ${ }^{\circ} 1$ 2, p.64-67, jan-fev, 2004.

PEREIRA, A.L.F.; VIDAL, T.F.; CONSTANT, P.B.L. Antioxidantes alimentares: importância química e biológica. Nutrire: rev. Soc. Bras. Alimento e Nutrição = Journal Brazilian Soc. Food Nutr., São Paulo, SP, v. 34, n.3, p. 231-247, dez. 2009. Disponível em: http://

www.vinovit.com.br/public/biblioteca-virtual/ semente-de-uva/antioxidantesalimentaresimportancia-quimica-e-biologica.pdf. Acesso em: 05 mar. 2012.

\section{PEREIRA, M. A. Perfil cromatográfico das} substâncias fenólicas presentes em extratos de mel de assa peixe e avaliação de seu poder antioxidante. 77 páginas. UFRJ - Instituto de Ciências Exatas/Química, Rio de Janeiro, Seropédica, 2010.

PORTO, M. Beba cerveja e colabore com seu coração. Estudos comprovam que cerveja, assim como o vinho, faz bem à saúde e auxilia na prevenção de doenças. Revista Beer life, jun. 2009, Ed. no 4, p.26-28. Disponível: http:// www.beerlife.com.br/ed5/revista/default.html Acesso em: 16 set. 2012.

SANTOS, R. C. Cerveja velha perde atividade antioxidante. Jornal da Unicamp, Campinas, 10/16 set. 2007, No 371, p.8. Disponível em: http:// www.unicamp.br/unicamp/unicamp_hoje / jornalPDF/ju371pag08.pdf Acesso em: 10 mar. 2012. 
SILVA, M. L. C.; COSTA, R. S.; SANTANA, S. S.; KOBLITZ, M. G. B. Compostos fenólicos, carotenóides e atividade antioxidante em produtos vegetais. Semina: Ciências Agrárias, Londrina, v. 31, n. 3, p.669-682, jul./ set. 2010 .

SIQUEIRAP.B.; BOLINI H.M.A.; MACEDO
G.A. O processo de fabricação da cerveja e seus efeitos na presença de polifenóis. Alimento e Nutrição., Araraquara v.19, n.4, p.491-498, out./ dez.2008.

URBIM, E.; TIRABOSCHI, J. Por que a lei seca salva 50 vidas por dia. Revista Galileu, São Paulo, SP, Ed. Globo, Ago. 2008, nº 205, p.52-65. 